\title{
Is the prevalence of the medication-related osteonecrosis of the jaws underestimated, evaluation in oncological and non- -oncological disease
}

\author{
Galis $\mathrm{B}^{1}$, Zajko $\mathrm{J}^{1}$, Hirjak $\mathrm{D}^{1}$, Vanko $\mathrm{L}^{1}$, Kupcova $\mathrm{I}^{1}$, Jurkemik $\mathrm{J}^{2}$, Gengelova $\mathrm{P}^{2}$, Mikuskova $\mathrm{K}^{2}$, \\ Halmova $\mathrm{K}^{3}$, Riznic $\mathrm{M}^{4}$, Czako L ${ }^{1}$ \\ Department of Oral and Maxillofacial Surgery of Medical Faculty of Comenius University and University \\ Hospital Bratislava, Bratislava, Slovakia. brano.galis@gmail.com
}

\begin{abstract}
OBJECTIVES: The purpose of this study was to evaluate the prevalence of medication-related osteonecrosis of the jaw in Slovak population and compare the literature findings, whether the prevalence of MRONJ is underestimated.

BACKGROUND: Antiresorptive drugs significantly increase quality of life, although during therapy, or in posttreatment period, osteonecrosis of the jaws might occur as a severe adverse effect. Medication-related osteonecrosis of the jaws (MRONJ) is a severe problem that has been observed in the past few years.

METHODS: This multi-centric study evaluates the prevalence in Slovak population, assesses the values from 4 largest centres of maxillofacial surgery in Slovakia (1166 patients with MRONJ) and provides the comparison of literature review.

RESULTS: Between 2010-2015, there was increasing number of newly diagnosed patients with MRONJ (1166 overall MRONJ patients) annually, except 2012 (mean growth of $123.88 \%$ ). This finding was supported by a statistical analysis of the rising tendency of prevalence in literature, where there was a significant difference in prevalence of non-oncologic patients before and after $2010 \mathrm{t}(15)=2.725, \mathrm{p}=0.016$. The 6-year prevalence was $1.34 \%$ in population with antiresorptive drugs intake, for osteoporosis $0.47 \%$, for breast cancer $4.10 \%$, prostate cancer $3.99 \%$ and multiple myeloma $21.26 \%$.

CONCLUSION: This study considers that there is a significant rising tendency of MRONJ in non-oncological patients, what could be caused by underestimation of the risk for development MRONJ in these patients. There should be a better cooperation and information among dentists and doctors indicating the antiresorptive treatment and strong emphasis on primary prevention before the initial treatment even in non-oncological patients (Tab. 5, Fig. 7, Ref. 69). Text in PDF www.elis.sk.

KEY WORDS: bisphosphonates, osteonecrosis, jaw, BRONJ, MRONJ, prevalence, antiresorptive drugs.
\end{abstract}

\section{Introduction}

Antiresorptive drugs (mainly bisphosphonates) are a group of medication widely used to inhibit bone loss by osteoporosis or as the agent against skeletal-related events as bone metastases in malignant disease (e.g. breast cancer, prostate cancer, lung, renal cancer and other organs) or in multiple myeloma, which has essentially a positive impact on quality of life $(1,2)$. Bisphospho-

${ }^{1}$ Department of Oral and Maxillofacial Surgery of Medical Faculty of Comenius University and University Hospital Bratislava, Bratislava, Slovakia, ${ }^{2}$ Department for Oral Surgery, Jessenius Medical Faculty of Comenius University, Martin, Slovakia, ${ }^{3}$ Department of Oral and Maxillofacial Surgery, St. Elizabeth Oncologic Clinic and Comenius University, Bratislava, Slovakia, and ${ }^{4}$ Department of Stomatology and Maxillofacial Surgery, PJ Safarik University, Kosice, Slovakia

Address for correspondence: B. Galis, Department of Oral and Maxillofacial Surgery of Medical Faculty of Comenius University and University Hospital Bratislava, Ruzinovska 6, SK-826 06 Bratislava, Slovakia. Phone: +421.2 .48234865$ nates are poorly absorbed in the gastrointestinal tract and almost immediately the resorbed dose is taken up by bone from plasma with a high affinity to bone hydroxyapatite (approximately half of resorbed dose), the rest is excreted by kidney in non-methabolised form. While the half-period of bisphosphonates in plasma is few hours, in the bone it is about 10 years (3-5). There are many adverse effects of antiresorptive drugs described in literature, such as atrial fibrilation, over-suppression of bone turnover, hypocalciemia, acute inflammatory response, severe musculoskeletal pain, esophageal irritation and erosion, but none has the attention of the osteonecrosis of the jaws (6). Since the medication-related osteonecrosis of the jaw (MRONJ, also known as bisphosphonates-related osteonecrosis of the jaw BRONJ, osteonecrosis of the jaw ONJ, antiresorptive drugs-related osteonecrosis of the jaw ARONJ) was first described by Marx in 2003 (7) as a severe side effect of antiresorptive drugs, the problem has been well monitored and welldescribed $(8,9)$. Determining the risk of developing the MRONJ is troublesome, however, intravenous application has a higher risk compared to per os administration used in non-malignant condi- 
tion $(6,10-13)$. The main factor for development of osteonecrosis is tooth extraction, followed by dental prosthesis irritation, periodontal and periapical disease, clinical findings accompanied by any type of inflammation $(9,14,15)$.

The definition of MRONJ was established by The American Association of Oral and Maxillofacial Surgeons (AAOMS) as an update of their definition of medication-related ONJ to:

- current or previous treatment with antiresorptive or antiangiogenic agents;

- exposed bone or bone that can be probed through an intraoral or extraoral fistula(e) in the maxillofacial region that has persisted for more than 8 weeks; and

- no history of radiation therapy to the jaws or obvious metastatic disease to the jaws.

The International Task Force on Osteonecrosis of the Jaw of the American Society for Bone and Mineral Research defines ONJ as:

- exposed bone in the maxillofacial region that does not heal within 8 weeks after identification by a health care provider;

- exposure to an antiresorptive agent; and

- no history of radiation therapy to the craniofacial region $(8,9)$.

The purpose of this article is to estimate the prevalence and incidence of MRONJ in Slovak population from 4 largest centres and compare oncological vs. non-oncological group, with the focus on the non-oncological patients, who are potentially a large group of risk patients in dentoalveolar treatment due to persistence of bisphosphonates in the skeletal tissue for years, even if therapy of primary disease was successfully finished.

\section{Materials and methods}

Methods

The design of the study was established on medical data, which was collected from January 2010 to December 2015 in the 4 referral centres of maxillofacial surgery in Slovakia (Department of Stomatology and Maxillofacial Surgery, L. Pasteur University Hospital in Kosice; Department of Stomatology and Maxillofacial Surgery, Comenius University, Faculty of Medicine and St. Elisabeth Cancer Institute, Bratislava, Slovakia; Department for Oral Surgery, Jessenius Faculty of Medicine, Comenius University, Martin, Slovakia, Department of Oral and Maxillofacial Surgery, Comenius University, University hospital of Bratislava) from medical records of adult patients. Each centre sent the data, which consisted of primary diagnosis treated with antiresorptive

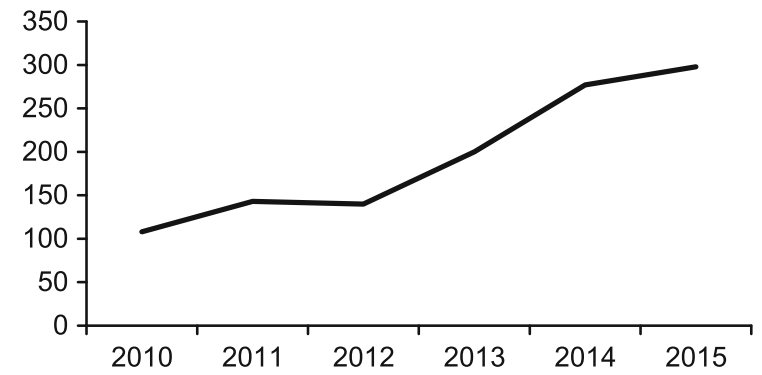

Fig. 1. Increasing number of the overall MRONJ patients annually.

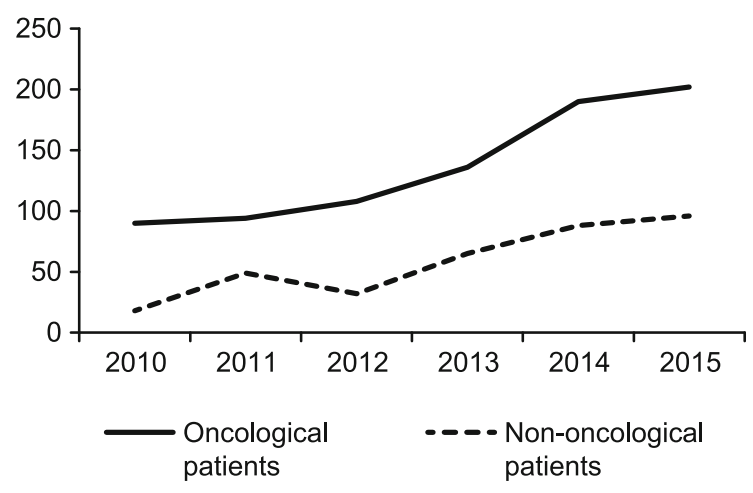

Fig. 2. Number of oncological and non-oncological (osteoporosis) patients by the years.

medicaments, sex, year of first visit (start of dispensarisation). Subsequently, the study assessed only the main oncological diagnoses and benign primary diagnose. The study included only the first-time diagnosed MRONJ patients from 2010 to 2015, the recurrences were excepted, and the MRONJ were assessed according to the definition of AAOMS stage 0-III (9), stages were not assessed in this study.

The data from medical records were compared yearly with an overall number of treated patients during years 2010-2015 and each other according to previous year for the assessment of an increasing or decreasing tendency of overall MRONJ occurrence. This comparison was also performed for the most frequent diagnoses (Fig. 1).

The numbers of national disease data were extracted from the National health information centre publications, which has been upgraded and published yearly. The National health information centre (NHIC) is a state-funded organization founded by the Ministry of Health of the Slovakia, which performs tasks in the area of health statistics and provision of library and information services in the field of medical sciences and health service. It administrates national health registries and national health administrative registries as well.

The patients were subsequently divided into 2 groups characterised by the primary disease, for which was the bisphosphonates therapy indicated. The study was focused on analysis of the prevalence in population, incidence of the disease in patients, who have undergone the antiresorptive treatment and the risk ratio for each of the most frequent diagnoses.

\section{Results}

These 4 largest regional centres covered approximately $72.29 \%$ of Slovak population (from 8 total number of regions 6 regions were covered in this multi-centric study except 2). It represents the population of 3919821 (male population of 1906668 , female 2013 153) (16). The total number of MRONJ group was 1166 patients (402 males $-34.48 \%, 764$ females $-65.52 \%$ ), which was divided to two study groups - oncological (819 patients $-70.24 \%$ ) and non-oncological patients (347 patients $-29.76 \%$ ). 
724-731

The number of patients in the oncological group was 819 (70.24 \% of overall MRONJ) (Fig. 2), in which 3 dominant diseases (670 patients) were evaluated more in detail. Multiple myeloma (156 patients, represent $13.38 \%$ from overall numbers, 58 males $(4.97 \%)$ and 98 females $(8.40 \%))$, breast carcinoma (316 females, $27.10 \%$ ), prostate carcinoma (198 males, $16.98 \%$ ), the rest of the patients (148 patients) were miscellaneous diagnoses

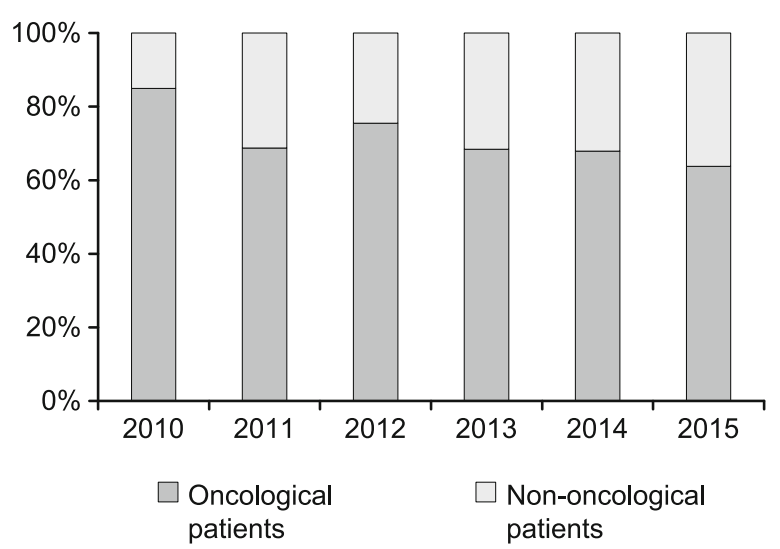

Fig. 3. Percentual representation of oncological and non-oncological patients with MRONJ per year.

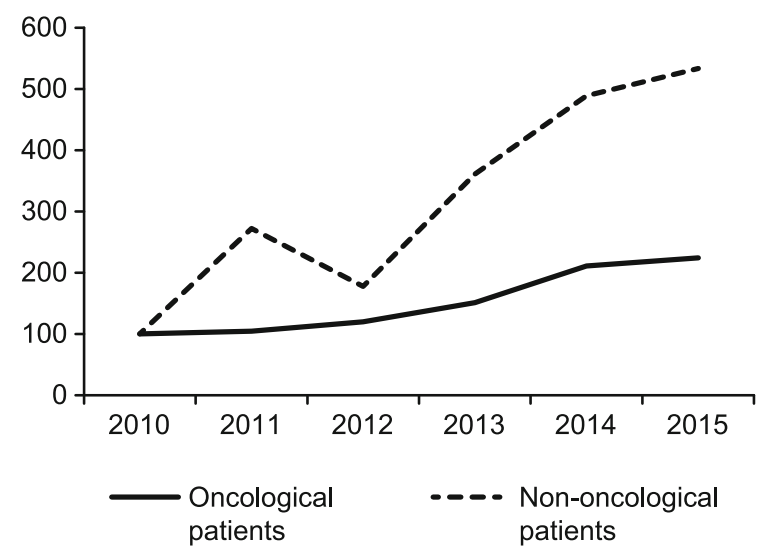

Fig. 4. The percentual changes of patients per year compare according to the first year assessed in study (2010). $p<0.0001$.

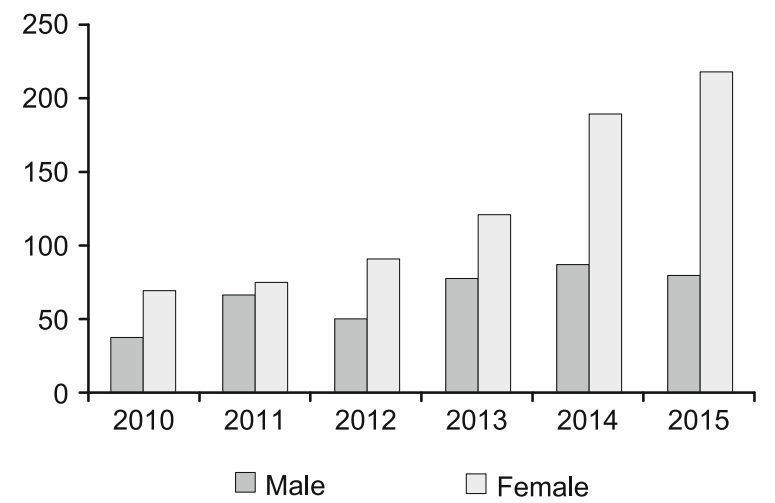

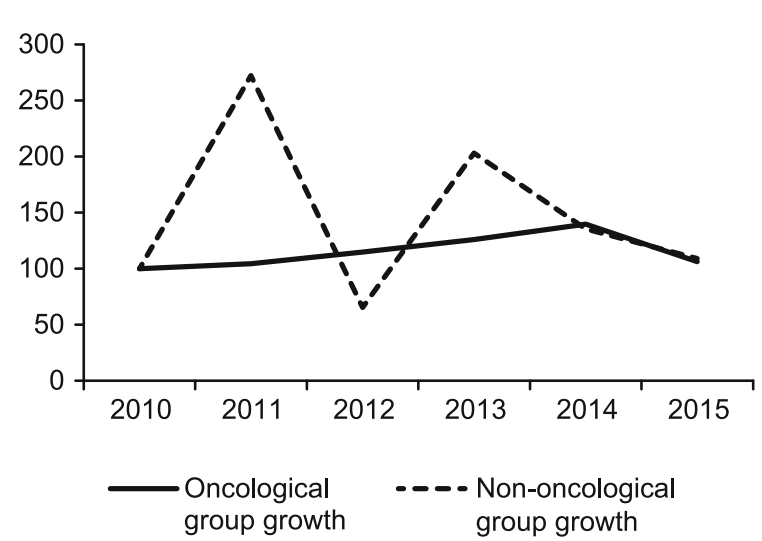

Fig. 5. The percentual changes in number of patients according the previous year.

like (kidney carcinoma, any types of lymphoma, etc.), which were not evaluated.

In the non-oncological group, MRONJ occurred in 348 patients. Osteoporosis (345 patients; $99.13 \%$ ), was absolutely dominant primary diagnosis in the non-oncological group represented by 348 patients $(29.85 \%$ of overall MRONJ), from whom 281 were females $(83.62 \%)$ and 64 males $(16.38 \%)$.

We extracted the numbers of 4 main diagnoses (multiple myeloma, breast carcinoma, prostate carcinoma, osteoporis) from NHIC publications, which were evaluated in this study and assessed the prevalence and incidence of MRONJ (Fig. 3). The numbers of MRONJ for each diagnose were associated with the prevalence of the oncological diagnose in Slovak population to estimate the incidence of MRONJ and the risk of occurrence. The total number of oncological diagnoses was considered as the summary of the new cases during the period despite of the success of treatment because MRONJ can occur independently from the therapy.

\section{Statistical analysis}

Statistical analysis (t-test, $\chi^{2}$ test, odds ratio and relative risk) was performed by SPSS v. 23 for Windows (SPSS Inc, Chicago, IL, USA). P values under 0.05 were considered significant. The prevalence of MRONJ was calculated to the population of covered area in this study during 2010-2015, in this period the prevalence

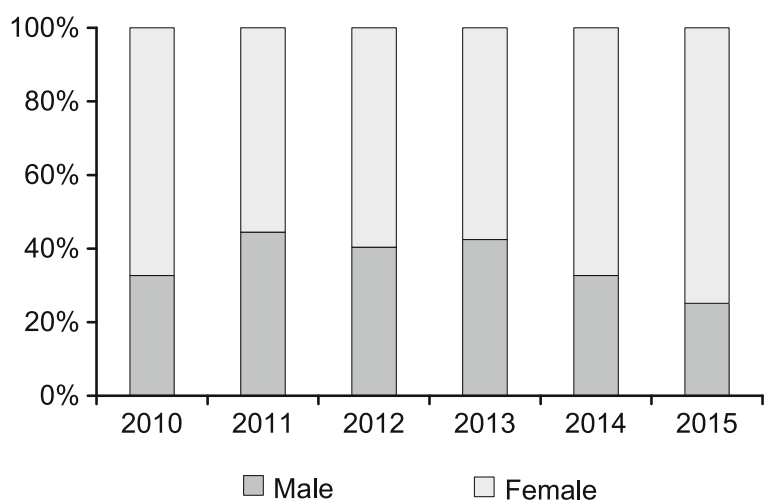

Fig. 6 and 7. Representation of sex for overall MRONJ per year. 
of MRONJ was 29.75 per 100000 . The incidence in our study was increased from 2.76 per 100000 to 7.60 per 100000 (Figs 4 and 5). Each year had increasing number of patients according to the newly diagnosed MRONJ, except for 2012. The female: male ratio was $1: 9$, with statistical difference between yearly occurrence of each sex in the study evaluated by $\mathrm{t}$ test $\mathrm{t}(10)=-2.7, p$ $=0.047$ (Figs 6 and 7).

The $t$ test was performed for the evaluation of the theoretical increasing/decreasing incidence in population by the comparison of yearly incidence to incidence in the first year of study. There was statistically a significant positive difference in the incidence between the first year of the study and subsequent years $\mathrm{t}(5)=$ 2.695, $\mathrm{p}=0.043$.

The relationship between the two groups was assessed. T-test revealed a significantly higher number of patients in the oncological group compared to the non-oncological group $\mathrm{t}(10)=3.34, \mathrm{p}=$ 0.008 . T test was performed to evaluate the raising ratio (number of patients compared to the first year of the study) in oncological and non-oncological group, there was no significant difference between yearly ratios of growth $\mathrm{t}(10)=1.014, \mathrm{p}=0.334$.

To identify the number of patients, who had undergone treatment by bisphosphonates, every health insurance company in Slovakia was inquired about the numbers of patients taking bisphosphonates in their evidence, however, only one insurance company answered. The answering company covers nearly quarter of all patients in Slovakia (27.92 \% from all patients), but with younger (active) insured patients according to the data of the insurance company (17). Antiresorptive drugs were used by 21116 patients in 2013 and 21300 in 2014 respectively. This represents the overall number of patients, who underwent bisphosphonates therapy in Slovakia of approximately 120000 , calculated from the proportion of the overall population and the compound of the patients in each insurance company. The portion of osteoporosis treated patients rose from $1.07 \%$ in 2001 to $5.08 \%$ in 2011, which represents about 100340 patients. The most prescribed drugs were ibandronate, risedronate, aledronate, denosumab and strontium ranelate (18).

To define the risk of MRONJ, we calculated the prevalence of the main diseases in the study from publications of the National Cancer registry (19-24) and the number of patients with osteoporosis in Slovakia (18). The yearly incidence was summed up during the last available years 2005-2010 (Tab. 1). However, it is necessary to realize, that the exact numbers of patients, who received the bisphosphonates or antiresorptive therapy in the following diagnoses is unknown. Because the bisphosphonates for intravenous administration are indicated in patients with symptomatic multiple myeloma, or in patients with skeletal-related events of primary cancer (estimate in breast cancer and prostate cancer approximately $70 \%$, in other diagnoses such as: lung, bladder and thyroid cancer in approximately $30 \%(25,26))$. Even other studies showed a lower incidence $(59.1 \%$ for breast cancer, $27.5 \%$ for prostate cancer and $18.6 \%$ for lungs) of bone metastasis, which were treated by bisphosphonates in about $60 \%$ by breast cancer and $23.7 \%$ for prostate cancer after 2000). In multiple myeloma, the bisphosphonates are not recommended according to guidelines in solitary plasmocytoma or asymptomatic myeloma, that represents the intake of bisphosphonates approximately in $62.9 \%$ (27).

According to bisphosphonates administration in the covered population, the number of patients with bisphosphonates treatment was recalculated, the recalculation was made to the estimated higher percentage of bisphosphonates administration (Tab. 2).

Chi-square test showed a significant relationship between MRONJ and oncological group $\chi^{2}(1, \mathrm{~N}=85941)=1985.915, \mathrm{p}=$ 0.000 . The oncological group was more likely to engage in MRONJ development than the non-oncological group (5\% to $0.5 \%$ ) with a relative risk 10.539 time (CI $95 \%=9.266-11.986)$ higher to development MRONJ (OR $=0.091$, CI $95 \%=0.079-0.103)$. The chi-square test was also provided for each main disease (Tab. 4).

There are many studies describing the prevalence of MRONJ. The articles to compare were included in the study according to the following criteria, available literature in English language, the keywords were ,prevalence“, ,risk“, ,bisphosphonate“ and „osteonecrosis of the jaw" in Pubmed, Scopus and Medline and 1150 English language articles were found. The articles were divided to 3 categories $-\mathrm{A}$ - articles with oncologic and non-oncologic groups, $\mathrm{B}$ - oncologic groups only with the main diagnoses followed in this article, $\mathrm{C}$ - non-oncologic/ osteoporosis groups (Tab. 3). The articles assessed a risk of specific treatment (teeth extraction, endodontic treatment). For full text review, 6 articles were in A category, 14 in B category and in C category, there were 10 articles included. The first authors and comparison between general

Tab. 1. The prevalence of the main diseases occurs in MRONJ study in Slovak population between 2005-2010.

\begin{tabular}{|c|c|c|c|c|c|c|c|}
\hline & 2005 & 2006 & 2007 & 2008 & 2009 & 2010 & total \\
\hline Multiple myeloma & 230 & 232 & 251 & 264 & 307 & 330 & 1614 \\
\hline Breast cancer & 2213 & 2293 & 2447 & 2665 & 2820 & 2787 & 15225 \\
\hline Prostate cancer & 1264 & 1355 & 1585 & 1758 & 1801 & 2051 & 9814 \\
\hline Osteoporosis & & & & & & & 231637 \\
\hline
\end{tabular}

Tab. 2. The numbers of the patients and estimated percentage of MRONJ according to study collected numbers of the patients with MRONJ.

\begin{tabular}{lccc}
\hline & Total & $\begin{array}{c}\text { Main diagnoses } \\
\text { of covered population in study }\end{array}$ & MRONJ \\
\hline Multiple myeloma & 1015 & 734 & 156 \\
Breast cancer & 10658 & 7705 & 316 \\
Prostate cancer & 6870 & 4966 & 198 \\
Osteoporosis & 100340 & 72536 & 344 \\
Total to estimated BP intake & 120000 & 86748 & 3.99 \\
\hline
\end{tabular}


Tab. 3. Literature review of MRONJ prevalence divided in A, B, C category according to reviewed study.

\begin{tabular}{|c|c|c|c|}
\hline Author & Year of study & Prevalence & Notes \\
\hline \multicolumn{4}{|l|}{ A Category } \\
\hline Murad et al (46) & 1999-2004 & $\begin{array}{l}0 \% \mathrm{NO} \\
1.4 \% \mathrm{O}\end{array}$ & $\mathrm{gm}$ \\
\hline Mavrokokki et al (47) & $2003-09 / 2005$ & $\begin{array}{c}0.88-1.15 \\
(6.67-9.1 \%)^{*} \mathrm{O} \\
0.12 \% \mathrm{NO}\end{array}$ & $\mathrm{dm}$ \\
\hline Hallmer et al (48) & 2003-2010 & $\begin{array}{c}0.024 \% \mathrm{NO} \\
2.8 \% \mathrm{O}\end{array}$ & $\mathrm{gm}$ \\
\hline Yuh et al (49) & 2006-2008 & $\begin{array}{c}1.12 \% \mathrm{O} \\
0.09 \% \mathrm{NO}\end{array}$ & $\mathrm{gm}$ \\
\hline Malden (50) & $8 / 2007-1 / 2011$ & $\begin{array}{l}34.8 \% \mathrm{O}^{*} \\
2.5 \% \mathrm{NO}^{*}\end{array}$ & $\mathrm{dm}$ \\
\hline Goodwin et al (51) & 2008-2013 & $\begin{array}{c}0.42 \% \mathrm{O} \\
0.05 \% \mathrm{NO}\end{array}$ & $\mathrm{gm}$ \\
\hline Ulmner et al (14) & $2007-2008$ & $\begin{array}{c}0.001 \% \mathrm{NO} \\
0.07 \% \mathrm{O}\end{array}$ & $\mathrm{dm}$ \\
\hline \multicolumn{4}{|l|}{ B Category } \\
\hline Dimopoulos et al (52) & $1995-2003$ & $7.4 \% \mathrm{MM}$ & gm \\
\hline Hoff et al (53) & 1996-2004 & $\begin{array}{c}1.2 \% \mathrm{BC} \\
2.4 \% \mathrm{MM}\end{array}$ & $\mathrm{gm}$ \\
\hline Bamias et al (52) & 1997-2003 & $\begin{array}{c}6.7 \% \\
9.9 \% \mathrm{MM} \\
2.9 \% \mathrm{BC} \\
6.5 \% \mathrm{PC} \\
\end{array}$ & $\mathrm{gm}$ \\
\hline Stumpe et al (54) & $2000-4 / 2006$ & $\begin{array}{c}0.94 \% \\
2.7 \% \mathrm{MM} \\
1.27 \% \mathrm{PC} \\
0.42 \%\end{array}$ & $\mathrm{gm}$ \\
\hline Wang et al (55) & $2000-2005$ & $\begin{array}{c}3.8 \% \mathrm{MM} \\
2.5 \% \mathrm{BC} \\
2.9 \% \mathrm{PC}\end{array}$ & $\mathrm{dm}$ \\
\hline Vahtsevanos et al (15) & $2000-2008$ & $\begin{array}{c}5 \% \\
8.5 \% \mathrm{MM} \\
3.1 \% \mathrm{BC} \\
4.9 \% \mathrm{PC}\end{array}$ & $\mathrm{dm}$ \\
\hline Zavras & $2001-2004$ & $0.14 \%$ & $\mathrm{dm}$ \\
\hline Quispe et al (34) & $2002-2007$ & $9 \% \mathrm{BC}$ & $\mathrm{gm}$ \\
\hline Thumbigere-Math et al (56) & $2003-2007$ & $\begin{array}{c}3.125 \% \\
4.04 \% \mathrm{BC} \\
6.74 \% \mathrm{MM} \\
2.33 \% \mathrm{PC}\end{array}$ & $\mathrm{dm}$ \\
\hline Boonyapakorn et al (57) & 07/2005-12/2006 & $\begin{array}{c}28 \% \\
17.24 \% \mathrm{MM} \\
50 \% \mathrm{BC} \\
33.3 \% \mathrm{PC}\end{array}$ & $\mathrm{dm}$ \\
\hline Chang et al (58) & 2005-2010 & $\begin{array}{c}7.7 \% \mathrm{BC} \\
8.7 \% \mathrm{MM}\end{array}$ & $\mathrm{gm}$ \\
\hline Vidal-Real et al (59) & 2006-2013 & $\begin{array}{c}12.9 \% \\
4.6 \% \mathrm{PC} \\
2 \% \mathrm{BC}\end{array}$ & $\mathrm{dm}$ \\
\hline Christodoulou et al (60) & 06/2007-06/2008 & $\begin{array}{l}2.6 \% \mathrm{BC} \\
9.1 \% \mathrm{PC}\end{array}$ & $\mathrm{gm}$ \\
\hline Cuevas-González et al (61) & 2011-2013 & $2.6 \% \mathrm{BC}+\mathrm{PC}$ & $\mathrm{dm}$ \\
\hline \multicolumn{4}{|l|}{ C Category } \\
\hline Etminan et al (62) & $4 / 1995-12 / 2002$ & $0.027 \%$ & $\mathrm{gm}$ \\
\hline Fellows et al (63) & 1995-2006 & $0.004 \%$ & gm \\
\hline Story (64) & $04 / 2000-04 / 2006$ & $0.12 \%$ & $\mathrm{dm}$ \\
\hline Baillargeon et al (12) & $2000-2007$ & $0.7 \%$ & $\mathrm{gm}$ \\
\hline Yamazaki et al(65) & $11 / 2000-10 / 2010$ & $0.46 \%-0.99 \%$ & $\mathrm{dm}$ \\
\hline Lapi et al (43) & $7 / 2003-12 / 2005$ & $0.046 \%$ & $\mathrm{gm}$ \\
\hline Grbic et al (66) & NA & $0.01-0.04 \%$ & $\mathrm{dm}$ \\
\hline Borromeo et al (67) & $3 / 2006-8 / 2006$ & $0.085 \%$ & $\mathrm{dm}$ \\
\hline Lo et al(68) & $01 / 2006-08 / 2008$ & $0.1 \%$ & $\mathrm{gm}$ \\
\hline Powell et al (69) & $11 / 2010-2 / 2011$ & $0.5 \%$ & $\mathrm{gm}$ \\
\hline
\end{tabular}

medicine first authors and dental/ maxillofacial surgeon authors were assessed and provided.

Based on the findings of this study, the comparison, and statistical evaluation ( $t$ test) of the literature review was performed. The first author was divided to general medicine and dental medicine group and the prevalence from the articles was compared for each category and main disease (Tab. 5). There was no significant difference. Subsequently, the articles were also divided according to the year of investigation, one group contained articles until 2010 and the second group contained articles since 2011. There was a significant difference of prevalence in non-oncological patients $\mathrm{t}(15)=2.725, \mathrm{p}=0.016$

\section{Discussion}

Indications of antiresorptive treatment improves patient's quality of life, but MRONJ is one of the severe adverse effect of their administration (28), however, the positive effect is still predominant (29-31). The risk of MRONJ development is increased by several factors, such as duration of BP therapy, administration route of BP, type of BP, invasive dental procedures or dental prostheses, oncological disease, caucasian origin and multiple myeloma (32-34). The literature review shows much lower incidences and prevalence numbers than was described in this study, but on the other hand, it is possible to find studies, where the numbers are very similar $(35,36)$. These studies were not included in literature review, because they were excluded in accordance with the literature review criteria. Some authors claim, that it is hard to define the prevalence generally or exactly, because there is an estimated undiagnosed disease in population of approximately $25 \%$, mainly stage 0 . (37) Therefore it is possible that the real number might be higher.

There were on average 2813 dental practices per year providing dental treatment in the observed period, which registered 4153 908 adult patients. The percentage of preventive examinations was in average $53.01 \%$ in adult patients. The average number of invasive interventions was 814999 per year, which represents approximately one extraction in 5 adult patients per year, and given the number of removable dentures 91680,1 per 50 patients (38-42).

The data in this study imply, that there are approximately 120 000 patients in risk, taking antiresorptive treatment, where the oncologic to non-oncologic patient's ratio is $1: 5$. Before, but also during the treatment, it is important to keep in mind the indication of antiresorptive treatment, whether it is due to malignancy or a benign condition.

Except for the primary cause and dental treatment there are co-factors of MRONJ mentioned in literature - namely the type of antiresorptive drug, its combination with immunosuppresive medication and the length of bisphosphonate treatment (43). The MRONJ is also connected with the risk of atypical femoral fractures (44).

It seems that the risk of MRONJ is higher in patients, who have been taking oral bisphosphonate for more than 5 years (45). This would explain the rising number of patients, which is described in this study. Patients may not be treated by bisphosphonates any- 
Tab. 4. Risk ratios for MRONJ development of the main diagnoses of the study.

\begin{tabular}{|c|c|c|c|c|c|}
\hline \multicolumn{6}{|c|}{ Risk Ratios for MRONJ development and CI $95 \%$} \\
\hline & Oncological group & Multiple myeloma & Breast cancer & Prostate cancer & Osteoporosis \\
\hline Oncological group & $\mathrm{x}$ & - & - & - & $10.539(9.266-11.986)$ \\
\hline Multiple myeloma & - & $\mathrm{x}$ & $0.193(0.162-0.230)$ & $0.188(0.154-0.228)$ & $44.815(37.633-53.367)$ \\
\hline Breast cancer & - & $0.193(0.162-0.230)$ & $\mathrm{x}$ & & $8.648(7.437-10.056)$ \\
\hline Prostate cancer & - & $0.188(0.154-0.228)$ & 1.029 (0.864-1.224) & $\mathrm{x}$ & 8.407 (7.075-9.990) \\
\hline Osteoporosis & $10.539(9.266-11.986)$ & $44.815(37.633-53.367)$ & $8.648(7.437-10.056)$ & 8.407 (7.075-9.990) & $\mathrm{x}$ \\
\hline
\end{tabular}

\begin{tabular}{|c|c|c|c|c|c|}
\hline \multicolumn{6}{|c|}{ OR and CI $95 \%$} \\
\hline & Oncological group & Multiple myeloma & Breast cancer & Prostate cancer & Osteoporosis \\
\hline Oncological group & $\mathrm{x}$ & - & - & - & $0.091(0.079-0.103)$ \\
\hline Multiple myeloma & - & $\mathrm{x}$ & $6.311(5.117-7.783)$ & $6.499(5.180-8.155)$ & $0.018(0.014-0.022)$ \\
\hline Breast cancer & - & $6.311(5.117-7.783)$ & $\mathrm{x}$ & $0.971(0.810-1.164)$ & $0.111(0.095-0.130)$ \\
\hline Prostate cancer & - & $6.499(5.180-8.155)$ & $0.971(0.810-1.164)$ & $\mathrm{x}$ & $0.115(0.096-0.137)$ \\
\hline Osteoporosis & $0.091(0.079-0.103)$ & $0.018(0.014-0.022)$ & $0.111(0.095-0.130)$ & $0.115(0.096-0.137)$ & $\mathrm{x}$ \\
\hline
\end{tabular}

Tab. 5. Comparison and statistical evaluation ( $t$ test) of literature review.

\begin{tabular}{lcc}
\hline Comparison & Groups & $\mathrm{p}$ \\
\hline Oncological patients overall & GM, DM & 0.148 \\
Oncological patients overall & Before 2010 and since 2011 & 0.229 \\
Non-oncological patients overall & GM, DM & 0.223 \\
Non-oncological patients overall & Before 2010 and since 2011 & 0.016 \\
Multiple myeloma & GM, DM & 0.387 \\
Multiple myeloma & Before 2010 and since 2011 & NA \\
Prostate cancer & GM, DM & 0.640 \\
Prostate cancer & Before 2010 and since 2011 & 0.749 \\
Breast cancer & GM, DM & 0.355 \\
Breast cancer & Before 2010 and since 2011 & 0.692 \\
\hline
\end{tabular}

GM - general medicine first author, DM - dental medicine first author, NA - test was not performed because of the absence necessary data

more, but because of the pharmacodynamic characteristic of this group of medicaments, they are in high risk of MRONJ from the long term point of view due to long persistence of the drug in bones (3-5). Probably this is the reason that the ,patient's reserve“ has been made and the MRONJ obtained even years lasting therapy without any complications.

Therefore, it is of great importance to ask about patient's personal history in detail and to ask also about past drug history.

It is necessary that interdisciplinary of national societies gave a statement on this subject and defined the way of treatment of these patients and gave a guideline for patients within primary prevention (before treatment), but also during secondary (during bisphosphonate treatment) and tertiary prevention (after development of MRONJ).

The calculated risk of the development for MRONJ is 1 patient with MRONJ per one dental office (during investigation period there were approximately 2800 dental offices in Slovakia) per 15 years in Slovakia. However, there are approximately 43 patients with risk per dental office.

\section{Conclusion}

The findings in this study showed an increasing tendency in numbers of MRONJ patients yearly, except for 2012, which was supported with the statistical analysis of comparison for older and newer literature. The study assessed that there were still signifi- cantly more oncological patients with MRONJ than non-oncological patients with 1.9 female: male ratio. The risk of MRONJ development is 10-times higher in the oncological group than in the non-oncological group, and the risk in multiple myeloma is 44time higher than in non-oncological patients (Tab. 4). The 6-year estimated prevalence for the covered population in Slovakia was $0.47 \%$ for osteoporosis, $3.99 \%$ for prostate cancer, $4.10 \%$ for breast cancer and $21.26 \%$ for multiple myeloma. The data about antiresorptive drugs usage from insurance company showed that there could be decreasing numbers of patients, to whom the antiresorptive treatment was administrated. Unfortunately, in Slovak population, a preventive dental examination is done in about $53 \%$ of adult population (38-42). According to the results in this study, primary prevention is strongly recommended before the start of antiresorptive treatment and preventive dental treatment should be more radical before an initial treatment in oncologic patients. It is necessary to investigate through medical and pharmacological history of the risk patients.

\section{References}

1. Russell RGG, Watts NB, Ebetino FH, Rogers MJ. Mechanisms of action of bisphosphonates: Similarities and differences and their potential influence on clinical efficacy. Osteoporos Int 2008; 19 (6): 733-759.

2. Russell RGG. Bisphosphonates: The first 40 years. Bone 2011; 49 (1): $2-19$.

3. Leyvraz S, Hess U, Flesch G, Bauer J, Hauffe S, Ford JM et al. Pharmacokinetics of pamidronate in patients with bone metastases. J Natl Cancer Inst 1992; 84 (10): 788-792.

4. Lin JH. Bisphosphonates: A review of their pharmacokinetic properties. Bone 1996; 18 (2): 75-85.

5. Russell R, Croucher P, Rogers M. Bisphosphonates: pharmacology, mechanisms of action and clinical uses. Osteoporos Int 1999; Suppl 2: S66-80.

6. Drake MT, Clarke BL, Khosla S. Bisphosphonates: Mechanism of Action and Role in Clinical Practice REVIEW. Mayo Clin Proc 2008; 83 (9): 1032-1045. 
7. Marx RE. Pamidronate (Aredia) and zoledronate (Zometa) induced avascular necrosis of the jaws: A growing epidemic. J Oral Maxillofac Surg 2003; 61 (9): 1115-1117.

8. Khan AA, Morrison A, Hanley DA, Felsenberg D, McCauley LK, O'Ryan F et al. Diagnosis and management of osteonecrosis of the jaw: A systematic review and international consensus. J Bone Miner Res 2015; 30 (1): 3-23.

9. Ruggiero SL, Dodson TB. American Association of Oral and Maxillofacial Surgeons position Paper on Medication-Related Osteonecrosis of the Jaws- 2014 Update. Am Assoc Oral Maxillofac Surg 2014; 72 (12): 2381-2382.

10. Wilkinson GS, Kuo YF, Freeman JL, Goodwin JS. Intravenous bisphosphonate therapy and inflammatory conditions or surgery of the jaw: A population-based analysis. J Natl Cancer Inst 2007; 99 (13): 1016-1024.

11. Baillargeon J, Kuo Y. Osteonecrosis of the jaw in older osteoporosis patients treated with intravenous bisphosphonates. Ann Pharmacother 2011; 45 (10): 1199-1206.

12. Baillargeon J, Kuo YF, Lin YL, Wilkinson GS, Goodwin JS. Osteonecrosis of the jaw in older osteoporosis patients treated with intravenous bisphosphonates. Ann Pharmacother 2011; 45 (10): 1199-1206.

13. Qi WX, Tang LN, He AN, Yao Y, Shen Z. Risk of osteonecrosis of the jaw in cancer patients receiving denosumab: A meta-analysis of seven randomized controlled trials. Int J Clin Oncol 2014; 19 (2): 403-410.

14. Ulmner M, Jarnbring F, Törring O. Osteonecrosis of the jaw in sweden associated with the oral use of bisphosphonate. J Oral Maxillofac Surg 2014; 72 (1): 76-82.

15. Vahtsevanos K, Kyrgidis A, Verrou E, Katodritou E, Triaridis S, Andreadis CG et al. Longitudinal cohort study of risk factors in cancer patients of bisphosphonate-related osteonecrosis of the jaw. J Clin Oncol 2009; 27 (32): 5356-5362.

16. National Health Information Center. Health Statistics Yearbook of the Slovakia 2015. In Bratislava; 2015, 9-34. www.nczisk.sk/Documents/ rocenky/2015/demografia.pdf

17. Správa o stave vykonávania verejného zdravotného poistenia za rok 2015. Bratislava. www.udzs.sk.sk/documents/77197/77937/Sprava +o+stave+vykonavania+VZP+za+rok+2015.pdf/850697da-ac29-42febc50-8fb168dcf4f4

18. Svedbom A, Hernlund E, Ivergård M, Compston J, Cooper C, Stenmark $\mathbf{J}$ et al. Osteoporosis in the European Union: A compendium of country-specific reports. Arch Osteoporos 2013; 8 (1-2).

19. Diba CS, Pleško I, Obšitníková A (Eds). Cancer incidence in the Slovakia 2005 Bratislava: National Health Information Center; 2009. 173. www.nczisk.sk/Documents/publikacie/analyticke/incidencia_zhubnych_ nadorov_2005.pdf

20. Diba CS, Pleško I, Hlava P (Eds). Cancer incidence in the Slovakia 2006 Bratislava: National Health Information Center; 2010. 177 p. www. nczisk.sk/Documents/publikacie/analyticke/incidencia_zhubnych_nadorov_2006.pdf

21. Diba CS, Pleško I, Hlava P (Eds). Cancer incidence in the Slovakia 2007 Bratislava; 2012. 135 p. www.nczisk.sk/Documents/publikacie/analyticke/incidencia_zhubnych_nadorov_2007.pdf

22. Diba CS, Pleško I (Eds). Cancer incidence in the Slovakia 2008 Bratislava: National Health Information Center; 2008. 176 p. www.nczisk. sk/Documents/publikacie/analyticke/incidencia_zhubnych_nadorov_ 2009.pdf
23. Diba CS (Ed). Cancer incidence in the Slovakia 2009 Bratislava: National Health Information Center; 2015192 p. www.nczisk.sk/Documents/ publikacie/analyticke/incidencia_zhubnych_nadorov_2009.pdf

24. Diba CS, Hlava P (Eds). Cancer incidence in the Slovakia 2010 Bratislava: NHIC; 2014. 186 p. www.nczisk.sk/Documents/publikacie/ analyticke/incidencia_zhubnych_nadorov_2010.pdf

25. Esler C. The non-surgical management of musculoskeletal malignancy. Orthop Trauma 2009; 23 (4): 258-265

26. Coleman RE, McCloskey EV. Bisphosphonates in oncology. Bone 2011; 49 (1): 71-76.

27. Anderson KC, Alsina M, Atanackovic D, Biermann JS, Chandler JC, Costello C et al. Multiple Myeloma, Version 2.2016: Clinical Practice Guidelines in Oncology. J Natl Compr Canc Netw 2015; 13 (11): 1398-1435.

28. Rizzoli R, Reginster J-Y, Boonen S, Bréart G, Diez-Perez A, Felsenberg $\mathbf{D}$ et al. Adverse Reactions and Drug-Drug Interactions in the Management of Women with Postmenopausal Osteoporosis. Calcif Tissue Int 2011; 89 (2): 91-104.

29. Ross JR, Saunders Y, Edmonds PM, Patel S, Wonderling D, Normand $\mathbf{C}$ et al. A systematic review of the role of bisphosphonates in metastatic disease. Health Technol Assess 2004; 8 (4): 1-176.

30. Kennel KA, Drake MT. Adverse Effects of Bisphosphonates: Implications for Osteoporosis Management. Mayo Clin Proc 2009; 84 (7): 632-638.

31. Khan A, Morrison A, Cheung A, Hashem W, Compston J. Osteonecrosis of the jaw (ONJ): diagnosis and management in 2015. Osteoporos Int 2016; 27 (3): 853-859.

32. Fung PPL, Bedogni A, Petrie A, Porter S, Campisi G, Bagan J et al. Time to onset of bisphosphonate-related osteonecrosis of the jaws: a multicentre retrospective cohort study. Oral Dis 2016; 23 (4): 477-483.

33. Bejhed RS, Kharazmi M, Hallberg P. Identification of Risk Factors for Bisphosphonate-Associated Atypical Femoral Fractures and Osteonecrosis of the Jaw in a Pharmacovigilance Database. Ann Pharmacother 2016; 50 (8): 616-624.

34. Quispe D, Shi R, Burton G. Osteonecrosis of the Jaw in Patients with Metastatic Breast Cancer: Ethnic and Socio-Economic Aspects. Breast J 2011; 17 (5): 510-513.

35. Rugani P, Luschin G, Jakse N, Kirnbauer B, Lang U, Acham S. Prevalence of bisphosphonate-associated osteonecrosis of the jaw after intravenous zoledronate infusions in patients with early breast cancer. Clin Oral Investig 2014; 18 (2): 401-407.

36. Walter C, Al-Nawas B, Grötz KA, Thomas C, Thü Roff JW, Zinser $\mathbf{V}$ et al. Prevalence and Risk Factors of Bisphosphonate-Associated Osteonecrosis of the Jaw in Prostate Cancer Patients with Advanced Disease Treated with Zoledronate. Eur Urol 2008; 54 (5): 1066-1072.

37. Fedele S, Bedogni G, Scoletta M, Favia G, Colella G, Agrillo A et al. Up to a quarter of patients with osteonecrosis of the jaw associated with antiresorptive agents remain undiagnosed. Br J Oral Maxillofac Surg 2015; 53 (1): 13-17.

38. Zubnolekárska starostlivost' v SR 2015. Štatistické prehl'ady 4/2016 Bratislava; 2016. www.nczisk.sk/Documents/publikacie/2015/ sp1604.pdf

39. Zubno lekárska starostlivost' v SR 2013. Štatistické prehl'ady 6/2014 Bratislava; 2014. www.nczisk.sk/Documents/publikacie/2013/ sp1406.pdf 
40. Zubnolekárska starostlivost'v SR 2014. Štatistické prehl'ady 04/2015 Bratislava; 2015. www.nczisk.sk/Documents/publikacie/2014/sp1504.pdf

41. Stomatologická starostlivost' v SR 2011. Edícia zdravotnícka štatistika 15/2012 Bratislava; 2012. www.nczisk.sk/Documents/publikacie/2011/zs1215.pdf

42. Stomatologická starostlivost' v SR 2012. Edícia zdravotnícka štatistika 15/2013 Bratislava; 2013. www.nczisk.sk/Documents/publikacie/2012/zs1315.pdf

43. Lapi F, Cipriani F, Caputi AP, Corrao G, Vaccheri A, Sturkenboom MC et al. Assessing the risk of osteonecrosis of the jaw due to bisphosphonate therapy in the secondary prevention of osteoporotic fractures. Osteoporos Int 2013; 24 (2): 697-705.

44. Graves LL, Bukata S V., Aghazadehsanai N, Chang TI, Garrett NR, Friedlander AH. Patients Receiving Parenteral Bisphosphonates for Malignant Disease and Having Developed an Atypical Femoral Fracture Are at Risk of Concomitant Osteonecrosis of the Jaw: An Evidence-Based Review. J Oral Maxillofac Surg 2016; 74 (12): 2403-2408.

45. Barasch A, Cunha-Cruz J, Curro FA, Hujoel P, Sung AH, Vena D et al. Risk Factors for Osteonecrosis of the Jaws: a Case-Control Study from the CONDOR Dental PBRN. J Dent Res 2011; 90 (4): 439-444.

46. Murad OM, Arora S, Farag AF. Bisphosphonates and osteonecrosis of the jaw: A retrospective study. Endocr Pract 2007; 13 (3): 232-238.

47. Mavrokokki T, Cheng A, Stein B, Goss A. Nature and Frequency of Bisphosphonate-Associated Osteonecrosis of the Jaws in Australia. J Oral Maxillofac Surg 2007; 65 (3): 415-423.

48. Hallmer F, Bjørnland T, Nicklasson A, Becktor JP, Andersson G. Osteonecrosis of the jaw in patients treated with oral and intravenous bisphosphonates: Experience in Sweden. Oral Surg Oral Med Oral Pathol Oral Radiol 2014; 118 (2): 202-208.

49. Yuh DY, Chang TH, Huang RY, Chien WC, Lin FG, Fu E. The national-scale cohort study on bisphosphonate-related osteonecrosis of the jaw in Taiwan. J Dent 2014; 42 (10): 1343-1352.

50. Malden N. Summary of: A study of 225 patients on bisphosphonates presenting to the bisphosphonate clinic at King's College Hospital. Bdj 2013; 214 (7): 350-351.

51. Goodwin JS, Zhou J, Kuo Y-F, Baillargeon J. Risk of Jaw Osteonecrosis After Intravenous Bisphosphonates in Cancer Patients and Patients Without Cancer. Mayo Clin Proc 2016; 1-8.

52. Bamias A, Kastritis E, Bamia C, Moulopoulos LA, Melakopoulos I, Bozas G et al. Osteonecrosis of the jaw in cancer after treatment with bisphosphonates: Incidence and risk factors. J Clin Oncol 2005; 23 (34): 8580-8587.

53. Hoff AO, Toth BB, Altundag K, Johnson MM, Warneke CL, Hu $\mathrm{M}$ et al. Frequency and Risk Factors Associated With Osteonecrosis of the Jaw in Cancer Patients Treated With Intravenous Bisphosphonates. J Bone Miner Res 2008; 23 (6): 826-36.

54. Stumpe MR, Chandra RK, Yunus F, Samant S. Incidence andrisk factors of bisphosphonate-associated osteonecrosis of the jaw. Head Neck 2009; 31 (2): 202-206.

55. Wang EP, Kaban LB, Strewler GJ, Raje N, Troulis MJ. Incidence of Osteonecrosis of the Jaw in Patients with Multiple Myeloma and Breast or Prostate Cancer on Intravenous Bisphosphonate Therapy. J Oral Maxillofac Surg 2007; 65 (7): 1328-1331.
56. Thumbigere-Math V, Tu L, Huckabay S, Dudek AZ, Lunos S, Basi DL et al. A Retrospective Study Evaluating Frequency and Risk Factors of Osteonecrosis of the Jaw in 576 Cancer Patients Receiving Intravenous Bisphosphonates. Am J Clin Oncol 2012; 35 (4): 386-392.

57. Boonyapakorn T, Schirmer I, Reichart PA, Sturm I, Massenkeil G. Bisphosphonate-induced osteonecrosis of the jaws: Prospective study of 80 patients with multiple myeloma and other malignancies. Oral Oncol 2008; 44 (9): 857-869.

58. Chang ST, Tenforde AS, Grimsrud CD, O'Ryan FS, Gonzalez JR, Baer DM et al. Atypical femur fractures among breast cancer and multiple myeloma patients receiving intravenous bisphosphonate therapy. Bone 2012; 51 (3): 524-527.

59. Vidal-Real C, Pérez-Sayáns M, Suárez-Penaranda JM, GándaraRey JM, García-García A. Osteonecrosis of the jaws in 194 patients who have undergone intravenous bisphosphonate therapy in Spain. Med Oral Patol Oral Cir Bucal 2015; 20 (3): e267-272.

60. Christodoulou C, Pervena A, Klouvas G, Galani E, Falagas ME, Tsakalos $\mathbf{G}$ et al. Combination of bisphosphonates and antiangiogenic factors induces osteonecrosis of the jaw more frequently than bisphosphonates alone. Oncology 2009; 76 (3): 209-211.

61. Cuevas-González MV, Díaz-Aguirre CM, Echevarría-y-Pérez E, Cuevas-González JC. Prevalence of osteonecrosis of the jaw and oral characteristics of oncologic patients treated with bisphosphonates at the General Hospital of Mexico. J Korean Assoc Oral Maxillofac Surg 2016; 42 (6): 365-369.

62. Etminan M, Aminzadeh K, Matthew IR, Brophy JM. Use of oral bisphosphonates and the risk of aseptic osteonecrosis: A nested case-control study. J Rheumatol 2008; 35 (4): 691-695.

63. Fellows JL, Rindal DB, Barasch A, Gullion CM, Rush W, Pihlstrom DJ et al. ONJ in Two Dental Practice-Based Research Network Regions. J Dent Res.2011; 90 (4): 433-438.

64. Story C. Bisphosphonate Use and the Risk of Adverse Jaw Outcomes This article has been cited by other articles : J Am Dent Assoc 2008; 139 (1): $1-2$.

65. Yamazaki T, Yamori M, Yamamoto K, Saito K, Asai K, Sumi E et al. Risk of osteomyelitis of the jaw induced by oral bisphosphonates in patients taking medications for osteoporosis: A hospital-based cohort study in Japan. Bone 2012; 51 (5): 882-887.

66. Grbic JT, Landesberg R, Lin S-Q, Mesenbrink P, Reid IR, Leung P-C et al. Incidence of Osteonecrosis of the Jaw in Women With Postmenopausal Osteoporosis in the Health Outcomes and Reduced Incidence With Zoledronic Acid Once Yearly Pivotal Fracture Trial. J Am Dent Assoc 2008; 139 (1): 32-40.

67. Borromeo GL, Brand C, Clement JG, McCullough M, Crighton L, Hepworth $\mathbf{G}$ et al. A large case-control study reveals a positive association between bisphosphonate use and delayed dental healing and Osteonecrosis of the jaw. J Bone Miner Res 2014; 29 (6): 1363-1368.

68. Lo JC, O'Ryan FS, Gordon NP, Yang J, Hui RL, Martin D et al. Prevalence of Osteonecrosis of the Jaw in Patients With Oral Bisphosphonate Exposure. J Oral Maxillofac Surg 2010; 68 (2): 243-253.

69. Powell D, Bowler C, Roberts T, Garton M, Matthews C, McCall I et al. Incidence of serious side effects with intravenous bisphosphonate: A clinical audit. Qjm 2012; 105 (10): 965-971. 